\title{
Dedication to Dr. Jeri Logemann
}

Dear friends,

On June 19th 2014 the journal of Dysphagia lost one of its original associate editors and the field of Deglutology one of its undisputed leaders, passionate teachers, legendary mentors, and forward thinking investigators; Dr. Jerilyn A. Logemann, the Ralph and Jean Sundin Professor of Communication Sciences and Disorders at Northwestern University.

As a leader, Dr. Logemann who was lovingly and respectfully called Jeri overcame seemingly insurmountable obstacles in the early days of development of our field and brought hope to dysphagic patients through her clinical acumen and research when it was commonly thought that there was little or no hope. As a teacher, Jeri contributed tirelessly to the education and training of a workforce of undergraduate and graduate students and staff to equip them with the skills, knowledge and compassion they needed to help improve the lives of countless patients. As a mentor, her legacy was to prepare many future leaders who would in their own right attain stardom. Jeri was passionate about the success of her mentees. When the last volunteer to complete the endoscopic studies for the future Dr. Bonnie Martin-Harris' thesis failed to show up in my laboratory, Jeri volunteered to take her place.

As a forward thinking investigator, Jeri indeed was a pioneer in trans-disciplinary research. She crossed disciplinary boundaries and incorporated new concepts and investigative devices into her research through collaborations involving rheology, manometry, rehabilitation, physiology, concurrent manometry and fluorography all instrumental in devising diet modifications, swallowing techniques and maneuvers to prevent aspiration, remedy dysphagia and improve quality of life.

Dr. Logemann was an inspiring role model from her early undergraduate and graduate years at Northwestern University to the end of her illustrious life as a tenured professor at the same institution. Dysphagia has made an unprecedented decision to use on the cover of this issue a photograph of the young Jeri Logemann when she had just embarked on her long and productive scientific and clinical career. This gesture not only pays homage to a long-time colleague, but also is symbolic that the future of our field and the improved well-being of our patients are in the hands of a young generation of multidisciplinary clinician investigators, who constitute the underpinnings of dysphagia care and the art and science of Deglutology - a mantle that Dr. Jeri Logemann carried so ably all her life.

Respectfully, Reza Shaker, MD Editor-in-Chief 